\title{
Amount Recovered Over Dosing Interval Normalized by Weight
}

National Cancer Institute

\section{Source}

National Cancer Institute. Amount Recovered Over Dosing Interval Normalized by

Weight. NCl Thesaurus. Code C102366.

The cumulative amount recovered from the specimen type specified in PPSPEC between doses (TAU) divided by weight. 